\section{Editorial}

Check for updates

\title{
Appropriate Use of Surgical Antibiotic Prophylaxis
}

\author{
Yee Gyung Kwak (1) \\ Department of Internal Medicine, Inje University Ilsan Paik Hospital, Goyang, Korea \\ - See the article "Appropriate Prophylactic Antibiotic Use in Clean Wound Surgery Under Local \\ Anesthesia” in volume 34, number 17, e135.
}

Surgical site infections (SSIs) are the leading cause of healthcare-associated infections and the development of SSI results in prolonged hospital stay, extra costs, and increased morbidity and mortality. ${ }^{1}$ Antibiotic prophylaxis to prevent SSI is one of the most widely accepted practices in surgery. ${ }^{2}$ Several guidelines for surgical antibiotic prophylaxis (SAP) have been published and there is considerable agreement in recommendations for antibiotic selection and timing, and duration of SAP. ${ }^{3}$ Optimal prophylaxis requires application to the appropriate types of operations, selection of safe and effective antibiotics, initial and additional antibiotic dose administration to maintain effective serum and tissue levels throughout the operation, and discontinuation when the patient is no longer receiving a benefit. ${ }^{2}$

This is an Open Access article distributed under the terms of the Creative Commons Attribution Non-Commercial License (https:// creativecommons.org/licenses/by-nc/4.0/) which permits unrestricted non-commercial use, distribution, and reproduction in any medium, provided the original work is properly cited.

ORCID iDs

Yee Gyung Kwak (D)

https://orcid.org/0000-0002-4713-8045

Disclosure

The author has no potential conflicts of interest to disclose.
Despite sufficient evidence of effectiveness, adherence to SAP guidelines is often suboptimal. ${ }^{2}$ In a previous study, the antibiotic dose was administered to $55.7 \%$ of patients within 1 hour before skin incision and antibiotics discontinued within 24 hours after surgery end time for only $40.7 \%$ of the patients. ${ }^{2}$ In Korea, only $15(0.8 \%)$ of 1,895 patients who underwent a major surgical procedure received antibiotic prophylaxis in accordance with published guidelines in 2004. ${ }^{1}$ SAP quality, especially the timing of administration of the first dose, was significantly improved after the national hospital evaluation program (NHEP) for SAP of major surgery was started in 2007. ${ }^{1}$ Although the duration of SAP significantly decreased overall, antibiotics were discontinued within 24 hours after the end of surgery for only $12(0.6 \%)$ among 1,949 surgical patients. ${ }^{1}$ Surgery under local anesthesia is currently not the subject of NHEP evaluation in Korea.

In this issue of the journal, Cha et al. ${ }^{4}$ compared the incidence of SSI in patients who received single-dose intravenous antibiotics only 1 hour before skin incision and those who received postoperative oral antibiotics only for 2-3 days in clean surgery under local anesthesia. They found that there was no difference in the incidence of SSI between the two groups. These results encourage and can be an important basis for surgeons to follow the SAP guidelines. They also demonstrated a low level of compliance to SAP guideline at the department of plastic surgery in 41 training hospitals in Korea. According to the telephone survey results, preoperative antibiotics were administered in $26.8 \%$ only and postoperative antibiotics were routinely prescribed at the time of discharge with a mean duration of 3.9 days. 
Low compliance with the SAP guidelines may be due to a lack of knowledge of the guidelines, disagreements with the recommendations and a misconception that extending SAP duration could reduce the risk of SSI. ${ }^{5}$ Adequate antibiotic timing is critical to the effectiveness of prophylaxis, and prolonged antibiotic administration can be harmful to patients by promoting antibiotic-resistant bacteria and increasing the incidence of antibiotic-associated complications. Antibiotic resistance is a global public health threat that has as one of the main causes the massive overuse of antibiotics. In Europe, the prevalence of hospital antibiotic use is $35 \%$ and over $10 \%$ of these prescriptions are destined for SAP. 5 Therefore, improving adherence to SAP guideline and appropriate use of SAP is an important element in the prevention of SSI and control of microbial resistance by preventing the selective pressure exerted by antibiotic use.

\section{REFERENCES}

1. Kim ES, Park SW, Lee CS, Kwak YG, Moon C, Kim BN. Impact of a national hospital evaluation program using clinical performance indicators on the use of surgical antibiotic prophylaxis in Korea. Int Infect Dis 2012;16(3):e187-92.

PUBMED | CROSSREF

2. Bratzler DW, Houck PM, Richards C, Steele L, Dellinger EP, Fry DE, et al. Use of antimicrobial prophylaxis for major surgery: baseline results from the National Surgical Infection Prevention Project. Arch Surg 2005;140(2):174-82. PUBMED | CROSSREF

3. Bratzler DW, Houck PM; Surgical Infection Prevention Guideline Writers Workgroup. Antimicrobial prophylaxis for surgery: an advisory statement from the National Surgical Infection Prevention Project. Am J Surg 2005;189(4):395-404. PUBMED | CROSSREF

4. Cha HG, Kwon JG, Han HH, Eom JS, Kim EK. Appropriate prophylactic antibiotic use in clean wound surgery under local anesthesia.J Korean Med Sci 2019;34(17):e135. CROSSREF

5. Schmitt C, Lacerda RA, Turrini RN, Padoveze MC. Improving compliance with surgical antibiotic prophylaxis guidelines: a multicenter evaluation. Am J Infect Control 2017;45(10):1111-5. PUBMED | CROSSREF 